\title{
PENGARUH LINGKUNGAN KERJA, KEPUASAN KOMPENSASI DAN STRES KERJA TERHADAP KINERJA PEGAWAI PADA DINAS PARIWISATA DAN KEBUDAYAAN KOTA PADANG
}

\author{
Vivi Nila Sari, SE,MM \\ Universitas Putra Indonesia YPTK Padang \\ E-mail: vivinilasari01@gmail.com
}

\begin{abstract}
Penilitian ini bertujuan untuk mengetahui seberapa besar Pengaruh Lingkungan Kerja, Kepuasan Kompensasi dan Stres Kerja Terhadap Kinerja Pegawai pada Dinas Pariwisata Dan Kebudayaan Kota Padang. Penelitian ini terdiri dari tiga variabel Independent yaitu Lingkungan Kerja Kepuasan Kompensasi Dan Stres Kerja dan satu variabel Dependent Kinerja Pegawai. Dengan alat analisisnya Analisis Analisis Deskriptif, Uji Validitas, Uji Reabilitas, Regresi Linier Berganda, Uji Determinasi $\left(R^{2}\right)$, Uji Hipotesis dan Uji F, Uji t. Metode pengumpulan data melalui survey dan mengedarkan kuesioner dengan sampel 75 orang responden. Hasil penelitian yang didapatkan berdasarkan Uji Parsial (Uji t) diperoleh : (a) Secara parsial terdapat pengaruh yang signifikan antara variabel Lingkungan Kerja terhadap Kinerja Pegawai. (b) Secara parsial terdapat pengaruh yang signifikan antara variabel Kepuasan Kompensasi terhadap Kinerja Pegawai. (c) Secara parsial tidak terdapat pengaruh yang signifikan antara variabel Stres Kerja dengan Kinerja Pegawai. Kemudian berdasar kan Uji Hipotesis secara simultan (Uji F) maka Lingkungan Kerja, Kepuasan Kompensasi dan Stres Kerja berpengaruh signifikan terhadap Kinerja Pegawai. Dan Uji Koefisien Determinasi $\left(R^{2}\right)$ Persentase Lingkungan Kerja, Kepuasan Kompensasi dan Stres Kerja terhadap Kinerja Pegawai sebesar 0,860 atau $86 \%$, sedangkan sisanya sebesar $14 \%$ dipengaruhi oleh variabel lain diluar penelitian ini. Akhirnya penulis menyarankan pada dinas Pariwisata Dan Kebudayaan Kota Padang untuk menjadikan Lingkungan Kerja, Kepuasan Kompensasi, Dan Stres Kerja sebagai bahan pertimbangan dalam meningkatkan kinerja Pegawai agar Visi dan Misi Intansi dapat berjalan dengan baik dan tujuan Intansi dapat dicapai secara maksimal.
\end{abstract}

Kata Kunci : Lingkungan Kerja, Kepuasan Kompensasi dan Stres Kerja

\section{PENDAHULUAN}

\subsection{Latar Belakang Masalah}

Semakin kerasnya kompetisi dunia usaha dewasa ini, memaksa perusahaan-perusahaan untuk memberdayakan dan mengoptimalkan segenap sumber daya yang mereka miliki guna mempertahankan kelangsungan hidup perusahaan. Sumber-sumber daya yang dimiliki setiap perusahaan sifatnya terbatas, jika perusahaan tidak dapat mengelola sumber daya yang dimiliki secara efisien dan efektif maka perusahaan tersebut cepat atau lambat akan mengalami kemunduran. Memahami pentingnya keberadaan SDM di era global saat ini salah satu upaya yang harus dicapai oleh perusahaan adalah dengan meningkatkan kualitas SDM. Dengan meningkatkan kualitas sumber daya manusia diharapkan pegawai dapat meningkatkan kinerjanya. Kinerja merupakan hasil kerja yang dapat dicapai oleh seorang atau sekelompok orang dalam organisasi, sesuai dengan wewenang dan tanggung jawab masing-masing dalam rangka upaya pencapaiyan tujuan organisasi secara legal, tidak melanggar hukum dan sesuai dengan moral maupun etika.Kondisi lingkungan kerja yang nyaman akan mempengaruhi pegawai bekerja lebih giat dan konsentrasi menyelesaikan tugas-tugasnya sesuai jadwal. Keberhasilan peningkatan kinerja menuntut instansi mengetahui sasaran kinerja. Jika sasaran kinerja ditumbuhkan dari dalam diri pegawai akan membentuk suatu kekuatan diri dan jika 
situasi lingkungan kerja turut menunjang maka pencapaian kinerja akan lebih mudah.Selanjutnya, setiap pegawai atau individu yang bekerja dalam suatu perusahaan mempunyai keinginan untuk mendapatkan gaji yang sesuai dan cocok dengan harapannya jika mereka mendapatkan gaji yang sesuai dengan harapannya maka mereka akan lebih bersemangat dalam bekerja. Faktor yang mempengaruhi kinerja karyawan diantaranya adalah kepuasan kompensasi karena kepuasan kompensasi dapat mempengaruhi perilaku karyawan untuk bekerja lebih bersemangat dan memacu tingginya kinerja.Dinas Pariwisata Dan Kebudayaan Kota Padang sebagai salah satu dinas pemerintahan yang bergerak dibidang pengembangan pariwisata dan kebudayaan kota padang Pencapaian kinerja Pegawai Dinas Pariwisata dan Kebudayaan Kota Padang dapat dikatakan belum optimal dan cenderung menurun. Jika terjadi penurunan kinerja pegawai setiap tahunnya maka akan berdampak negatif bagi perusahaan karena dapat menghambat produktivitas perusahaan. Indikasi permasalahan di lapangan terletak pada kepuasan kompensasi yang dirasa kurang terutama masalah gaji.

\section{LANDASAN TEORI}

\section{Lingkungan Kerja}

Lingkungan kerja merupakan suatu faktor yang secara tidak langsung mempengaruhi kinerja pegawai. Lingkungan kerja yang kondusif memberikan rasa aman dan memungkinkan para pegawai untuk dapat berkerja optimal. Lingkungan kerja mempunyai pengaruh langsung terhadap pegawai dalam menyelesaikan tanggung jawab kepada organisasi.Lingkungan kerja merupakan segala sesuatu yang ada disekitar para pekerja dan yang dapat mempengaruhi dirinya dalam menjalankan tugas-tugas yang dibebankan, misalnya kebersihan, musik, penerangan dan lain-lain Sunyoto, (2013:43).

\section{Kompensasi}

Kompensasi merupakan sesuatu yang diterima oleh karyawan sebagai imbalan jasa mereka terhadap perusahaan. Seorang karyawan menghargai sebuah kerja keras dan akan menunjukkan loyalitasnya kepada perusahaan. Hani Handoko (2012:23) berpendapat bahwa kompensasi mencerminkan ukuran karya mereka di antara para karyawan itu sendiri, keluarga dan masyarakat. Mathis dan Jackson (2012:125) menyatakan bahwa salah satu cara untuk meningkatkan prestasi kerja, memotivasi dan meningkatkan kinerja para karyawan adalah melalui kompensasi.

\section{Stres Kerja}

Stres terlalu besar dapat mengancam kemampuan seseorang untuk menghadapi lingkungan kerjanya Sebagai hasilnya, pada diri karyawan berkembang berbagai macamsegala stress yang dapat mengganggu pelaksanaan kerja mereka. Orang-orang yang mengalami bisamenjadi pemarah dan kehawatiran yang berlebihan. Sedangkan Menurut Manurung Dalam Mochamad Syafii (2016:17). Mengatakan stres kerja yang dialami tenagakerja sebagai hasil atau akibat dari proses bekerja, yang dapat berkembang menjadi tenaga kerja sakit fisik dan mental, sehingga tidak dapat bekerja secara obtimal.

\section{Kinerja}

Kinerja merupakan tingkat keberhasilan karyawan dalam menyelesaikan pekerjaannya. Kinerja bukan merupakan karakteristik individu, seperti bakat atau kemampuan, namun merupakan hasil dari perwujudan bakat atau kemampuan itu sendiri. Kinerja merupakan perwujudan dari kemampuan dalam bentuk karya nyata. 
Menurut Mangkunegara (2013:67) pengertian kinerja adalah hasil kerja secara kualitas dan kuantitas yang dicapai oleh seorang karyawan dalam melaksanakan tugasnya sesuai dengan tanggung jawab yang diberikan kepadanya.

\section{METODOLOGI PENELITIAN}

\subsection{Objek Penelitian}

Penelitian ini dilakukan pada kantor Dinas Pariwisata Dan Kebudayaan, Jalan Gadaria.No 56, Kota Padang, Sumatera Barat, sebagai salah satu instansi pemerintahan yang bergerak dibidang Pengembangan Pariwisata Dan Kebudayaan dikota Padang.

\subsection{Populasi dan Sampel \\ Populasi}

Populasi adalah wilayah generalisasi yang terdiri dari atas obyek atau subyek yang mempunyai kualitas dan karakteristik tertentu yang diterapkan oleh peneliti untuk dipelajari dan kemudian ditarik kesimpulannya. Dalam penelitian ini, populasi yang digunakan adalah seluruhnya yaitu 75 pegawai Dinas Pariwisata dan kebudayaan kota padang.

\section{Sampel}

Menurut Arikunto (2012:108) dalam suatu penelitian bilamana populasinya kurang dari 100 maka sebaiknya diambil seluruhnya, dan bilamana populasinya lebih dari 100 maka dapat diambil sebagian dari populasi yang ada.

Jumlah populasi Pegawai Dinas Pariwisata dan kebudayaan adalah 75 subjek. Maka peneliti mengambil seluruh pegawai yang berkerja sebagai sampel dalam penelitian ini.

\subsection{Teknik Analisis Data}

Menurut Sugiyono (2015:244), Analisis data adalah peoses mencari dan menyusun secara sistematis data yang diperoleh dari hasil wawancara, catatan lapangan dan dokumentasi, dengan cara mengorganisir data kedalam kategori, menjabarkan kedalam unit-unit, melakukan sintesa, menyusun kedalam pola, memilih mana yang penting dan akan dipelajari,dan membuat kesimpulan sehingga mudah di fahami oleh diri sendiri maupun orang lain.

Adapun teknik analisis data yang digunakan dalam penelitian ini adalah analisis Regresi Berganda, menggunakan SPSS 23.0 for windows.

\section{HASIL PENELITIAN DAN PEMBAHASAN}

\section{Analisis Korelasi}

\section{Tabel 6}

Korelasi Antara Variable-variable Bebas (independent) Correlation

Hasil Analisis Korelasi Variabel Lingkungan Kerja (X1), Kepusan Kompensasi (X2), Stres Kerja (X3), dan Kinerja Pegawai (Y) Correlations

\begin{tabular}{|ll|r|r|r|r|}
\hline & & $\begin{array}{c}\text { Lingkungan } \\
\text { Kerja }\end{array}$ & $\begin{array}{c}\text { Kepuasan } \\
\text { Kompensasi }\end{array}$ & $\begin{array}{c}\text { Stres } \\
\text { Kerja }\end{array}$ & \multicolumn{1}{c|}{$\begin{array}{c}\text { Kinerja } \\
\text { Karyawan }\end{array}$} \\
\hline Lingkungan Kerja & Pearson Correlation & 1 & $.878^{* *}$ & $.751^{* *}$ & $.867^{* *}$ \\
& Sig. (2-tailed) & & .000 & .000 & .000 \\
& $\mathrm{~N}$ & 75 & 75 & 75 & 75 \\
\hline Kepuasan & Pearson Correlation & $.878^{* *}$ & 1 & $.787^{* *}$ & $.921^{* *}$ \\
Kompensasi & Sig. (2-tailed) & .000 & & .000 & .000
\end{tabular}




\begin{tabular}{|c|c|c|c|c|c|}
\hline & $\mathrm{N}$ & 75 & 75 & 75 & 75 \\
\hline \multirow[t]{3}{*}{ Stres Kerja } & Pearson Correlation & $.751^{\star \star}$ & $.787^{* \star}$ & 1 & $.713^{* *}$ \\
\hline & Sig. (2-tailed) & .000 & .000 & & .000 \\
\hline & $\mathrm{N}$ & 75 & 75 & 75 & 75 \\
\hline \multirow[t]{3}{*}{ Kinerja Karyawan } & Pearson Correlation & $.867^{\star \star}$ & $.921^{\star \star}$ & $.713^{\star \star}$ & 1 \\
\hline & Sig. (2-tailed) & .000 & .000 & .000 & \\
\hline & $\mathrm{N}$ & 75 & 75 & 75 & 75 \\
\hline
\end{tabular}

Sumber : Data Primer Diolah, 2017

Interprestasi dari hasil analisis tabel 6 diatas dapat dilihat korelasi antara masing-masing variabel, yaitu :

1. Korelasi antara variabel Lingkungan Kerja dan Kepuasan Kompensasi adalah 0,878 hubungan variabel sempurna, dengan nilai probabilitas $0,000<0,005$ sehingga dapat disimpulkan bahwa kedua variabel signifikan.

2. Korelasi antara Lingkungan Kerja dan Stres Kerja adalah 0,751 hubungan variabel sempurna, dengan nilai probabilitas $0,000<0,005$ sehingga dapat disimpulkan bahwa keduanya variabel signifikan.

3. Korelasi antara Lingkungan Kerja dan Kinerja Pegawai adalah 0,867 hubungan variabel sempurna, dengan nilai probabilitas $0,000<0,005$ sehingga dapat disimpulkan bahwa keduanya variabel tidak signifikan.

4. Korelasi antara Kepuasan Kompensasi dan Stres Kerja adalah 0,787 hubungan variabel sempurna, dengan nilai probabilitas $0,000<0,005$ sehingga dapat disimpulkan bahwa keduanya variabel signifikan.

5. Korelasi antara Kepuasan Kompensasi dan Kinerja Pegawai adalah 0,921 hubungan variabel sempurna, dengan nilai probabilitas $0,000<0,005$ sehingga dapat disimpulkan bahwa keduanya variabel signifikan.

6. Korelasi antara Sters Kerja dan Kinerja Pegawai adalah 0,713 hubungan variabel sempurna, dengan nilai probabilitas $0,000<0,005$ sehingga dapat disimpulkan bahwa keduanya variabel tidak signifikan.

\section{Analisis Regresi Berganda}

\section{Tabel 7}

Analisis Regresi Berganda Pengaruh Lingkungan Kerja, Kepuasan Kompensasi, Stres Kerja Terhadap Kinerja Pegawai pada Dinas Pariwisata Dan Kebudayaan Kota Padang Coefficients $^{a}$

\begin{tabular}{|c|c|c|c|c|c|c|}
\hline \multirow{2}{*}{\multicolumn{2}{|c|}{ Model }} & \multicolumn{2}{|c|}{$\begin{array}{l}\text { Unstandardized } \\
\text { Coefficients }\end{array}$} & \multirow{2}{*}{$\begin{array}{c}\text { Standardized } \\
\text { Coefficients } \\
\text { Beta }\end{array}$} & \multirow[b]{2}{*}{$t$} & \multirow[b]{2}{*}{ Sig. } \\
\hline & & B & $\begin{array}{l}\text { Std. } \\
\text { Error }\end{array}$ & & & \\
\hline \multirow[t]{3}{*}{1} & (Constant) & .254 & .212 & & 1.197 & .235 \\
\hline & $\begin{array}{l}\text { Lingkungan } \\
\text { Kerja }\end{array}$ & 1.597 & .542 & .274 & 2.945 & .004 \\
\hline & $\begin{array}{l}\text { Kepuasan } \\
\text { Kompensasi }\end{array}$ & 4.628 & .622 & .740 & 7.436 & .000 \\
\hline
\end{tabular}




\begin{tabular}{|l|l|l|l|l|l|}
\hline Stres Kerja & -.120 & .115 & -.075 & -1.038 & .303 \\
\hline
\end{tabular}

a. Dependent Variable: Kinerja Pegawai

Sumber : Data Primer Diolah, 2017

Berdasarkan tabel 7 diatas maka dapat dilihat persamaan regresinya yaitu :

$$
\mathrm{Y}=0,254+1,597 \mathrm{X} 1+4,628 \mathrm{X} 2-0,120 \mathrm{X} 3+\mathrm{e}
$$

Interprestasi berdasarkan persamaan tersebut dapat diartikan sebagai berikut :

1. Konstanta sebesar 0,254 artinya apabila Lingkungan Kerja, Kepuasan Kompensasi dan Stres Kerja tidak ada atau diabaikan maka Kinerja Pegawai tetap sebesar konstanta 0,254 satuan atau $25,4 \%$.

2. Koefisien regresi positif sebesar 1,597 artinya apabila Lingkungan Kerja ditingkatkan sebesar satu satuan, dengan asumsi Kepuasan Kompensasi Dan Stres Kerja diabaikan, maka akan mengakibatkan kenaikan Kinerja Pegawai sebesar 1,597 satuan atau $159.7 \%$.

3. Koefisien regresi positif sebesar 4,628 artinya apabila Kepuasan Kompensasi ditingkatkan sebesar satu satuan, dengan asumsi Lingkungan Kerja Dan Stres Kerja diabaikan, maka akan mengakibatkan kenaikan Kinerja Pegawai sebesar 4,628 satuan atau 462.8\%

4. Koefisien regresi negatif sebesar -0,120 artinya apabila Stres Kerja ditingkatkan sebesar satu satuan, dengan asumsi Lingkungan Kerja Dan Kepuasan Kompensasi diabaikan, maka akan mengakibatkan penurunan Kinerja Pegawai sebesar -0,120 satuan atau -12 \%.

\section{Pengujian Hipotesis}

\section{Pengujian Hipotesis Secara Parsial (Uji-t)}

\section{Tabel 8}

Pengujian Hipotesis Secara Parsial (Uji T) Coefficients $^{\mathrm{a}}$

\begin{tabular}{|c|c|c|c|c|c|c|}
\hline & \multirow{2}{*}{ Model } & \multicolumn{2}{|c|}{$\begin{array}{c}\text { Unstandardized } \\
\text { Coefficients }\end{array}$} & \multirow{2}{*}{$\begin{array}{c}\begin{array}{c}\text { Standardized } \\
\text { Coefficients }\end{array} \\
\text { Beta }\end{array}$} & \multirow[b]{2}{*}{$\mathrm{T}$} & \multirow[b]{2}{*}{ Sig. } \\
\hline & & B & $\begin{array}{l}\text { Std. } \\
\text { Error }\end{array}$ & & & \\
\hline \multirow[t]{4}{*}{1} & (Constant) & .254 & .212 & & 1.197 & .235 \\
\hline & $\begin{array}{l}\text { Lingkungan } \\
\text { Kerja }\end{array}$ & 1.597 & .542 & .274 & 2.945 & .004 \\
\hline & $\begin{array}{l}\text { Kepuasan } \\
\text { Kompensasi }\end{array}$ & 4.628 & .622 & .740 & 7.436 & .000 \\
\hline & Stres Kerja & -.120 & .115 & -.075 & -1.038 & .303 \\
\hline
\end{tabular}

a. Dependent Variable: Kinerja Karyawan

Sumber : Data Primer Diolah, 2017

Dari tabel 8 diatas dapat diinterprestasikan sebagai berikut :

1. Pengaruh Lingkungan Kerja (X1) terhadap Kinerja Pegawai (Y) dari tabel 4.17 diatas terlihat t-hitung 2,945 dan t-tabel 1.996 dimana t-hitung lebih besar dari t-tabel $(2,945$ $>1.996)$ atau tingkat signifikan lebih kecil dari pada alpha $(0,004<0,05)$ maka dapat diperoleh $H_{0}$ ditolak $H_{a}$ diterima.

2. Pengaruh Kepuasan Kompensasi (X2) terhadap Kinerja Pegawai (Y) dari tabel 4.17 diatas terlihat t-hitung 7,436 dan t-tabel 1,996 dimana t-hitung lebih besar dari ttabel $(7,436>1,996)$ atau tingkat signifikan lebih kecil dari pada alpha $(0,000<0,05)$ maka dapat diperoleh $H_{0}$ ditolak $H_{a}$ diterima.

3. Pengaruh Sters Kerja (X1) terhadap Kinerja Pegawai (Y) dari tabel 4.17 diatas terlihat t-hitung -1,038 dan t-tabel 1,996 dimana t-hitung lebih kecil dari t-tabel $(-1,038<$ 1,996) atau tingkat signifikan lebih besar dari pada alpha $(0,303>0,05)$ maka dapat diperoleh $H_{0}$ diterima $H_{a}$ ditolak. 


\title{
Pengujian Hipotesis Secara Bersama-sama (Uji-F)
}

\author{
Tabel 9
}

Pengujian Hipotesis Secara Bersama-Sama (Uji F) ANOVA $^{\mathrm{a}}$

\begin{tabular}{|ll|r|r|r|r|r|}
\hline Model & Sum of Squares & Df & Mean Square & F & Sig. \\
\hline 1 & Regression & 24.661 & 3 & 8.220 & 152.661 & $.000^{\mathrm{b}}$ \\
& Residual & 3.823 & 71 & .054 & & \\
& Total & 28.484 & 74 & & & \\
\hline
\end{tabular}

a. Dependent Variable: Kinerja Pegawai

b. Predictors: (Constant), Stres Kerja, Lingkungan Kerja, Kepuasan Kompensasi Sumber : Data Primer Diolah, 2017

Dari tabel 9 di atas dapat dilihat pengujian ini dilakukan dengan cara membandingkan nilai $F_{\text {hitung }}$ dangan $F_{\text {tabel }}$, karena nilai $F_{\text {hitung }}$ lebih besar dari nilai $F_{\text {tabel }}(152,661>2,73)$. Dengan tingkat signifikan 0,000 lebih kecil dari 5\%. Maka diperoleh $H_{0}$ ditolak $H_{a}$ diteima, yang berarti hal ini dilakukan secara bersama-sama antara Lingkungan Kerja, Kepuasan Kompensasi, dan Stres Kerja berpengaruh signifikan terhadap Kinerja Pegawai.

\section{Koefisien Determinasi $\left(R^{2}\right)$}

\section{Tabel 10}

Hasil Pengujian Determinasi

\begin{tabular}{|c|c|c|c|c|}
\hline \multicolumn{5}{|c|}{ Model Summary ${ }^{b}$} \\
\hline Model & $\mathrm{R}$ & R Square & $\begin{array}{l}\text { Adjusted R } \\
\text { Square }\end{array}$ & $\begin{array}{l}\text { Std. Error of the } \\
\text { Estimate }\end{array}$ \\
\hline 1 & $.930^{\mathrm{a}}$ & .866 & .860 & .23205 \\
\hline
\end{tabular}

Berdasarkan tabel 10 diatas diperoleh angka Adjusted Square sebesar 0,860 hal ini menunjukan bahwa sumbangan variabel Lingkungan Kerja, Kepuasan Kompensasi, Stres Kerja Terhadap Kenerja Pegawai sebesar 0,860 atau $86 \%$ sedangkan sisanya sebesar $14 \%$ dipengaruhi variabel lain.

\section{Kesimpulan}

1. Lingkungan Kerja secara parsial berpengaruh positif dan signifikan terhadap Kinerja Pegawai pada Dinas Pariwisata dan Kebudayaan Kota Padang.

2. Kepuasan Kompensasi secara parsial berpengaruh positif dan signifikan terhadap Kinerja Pegawai pada Dinas Pariwisata dan Kebudayaan Kota Padang.

3. Stres Kerja secara parsial terdapat pengaruh negatif dan tidak signifikan terhadap Kinerja Pegawai pada Dinas Pariwisata dan Kebudayaan Kota Padang.

4. Bahwa secara bersama-sama terdapat pengaruh yang signifikan antara Lingkungan Kerja, Kepuasan Kompensasi dan Stres Kerja terhadap Kinerja Pegawai Dinas Pariwisata Dan Kebudayaan Kota Padang.

\section{Saran}

1. Bagi Perusahaan

Adapun saran bagi Perusahaan adalah sebagai berikut : 
a. Dinas Pariwisata Dan Kebudayaan Kota Padang diharapkan dapat meningkatkan Lingkungan Kerja pegawai dengan cara memberikan fasilitas yang dibutuhkan bagi pegawai dan memberikan keamanan dan kesejahteraan bagi pegawai. Dengan demikian Kinerja Pegawai Dinas Pariwisata Dan Kebudayaan Kota Padang akan meningkat.

b. Dinas Pariwisata Dan Kebudayaan Kota Padang diharapkan dapat meningkatkan Kepuasan Kompensasi Pegawai dengan memberikan insenif yang sesuai dengan imbalas atas kinerja yang telah dilakukan pegawai sehingga dapat meningkatkan Kinerja Pegawai Dinas Pariwisata Dan Kebudayaan Kota Padang.

c. Dinas Pariwisata Dan Kebudayaan Kota Padang diharapkan dapat menurunkan Stres Kerja dengan mengurangi beban pekerjaan pegawai serta memberikan penghargaan bagi pegawai yang berprestasi. Dengan demikian Kinerja Pegawai Dinas Pariwisata Dan Kebudayaan Kota Padang akan menigkat.

2. Bagi Peneliti Selanjutnya

a. Peneliti selanjutnya dapat mengembangkan hasil penelitian ini dan melibatkan variabel-variabel yang relevan yang berkaitan dengan Kinerja Pegawai. Dengan harapan hasil penelitian lebih akurat dan memiliki manfaat yang jauh lebih besar, sehingga perusahaan dapat meningkatkan Kinerja Pegawai pada tahun - tahun berikutnya.

b. Menjadikan Kepuasan Kerja sebagai variabel Intervening maka hasilnya akan berbeda.

\section{DAFTAR PUSTAKA}

A.A. Anwar Prabu Mangkunegara. 2013. Sumber Daya Manusia Perusahaan. Bandung: PT. Remaja Rosdakarya

Algifari. 2012. Analisis Regresi (Edisi 2). Yogyakarta: BPFE

Cahyani, Dwi, Moekti, Sinta. 2017. Pengaruh Motivasi dan Lingkungan Kerja Studi Empiris PT Misaja Mitra Pati. Skripsi diterbitkan.Surakarta : Universitas Muhamadiah Surakarta.

Dr. Suharsimi Arikunto. 2012. Prosedur Penelitian Suatu Pendekatan Praktik. Jakarta: PT. Rineka Cipta

Handoko, T. H. 2014. Manajemen Personalia dan Sumber Daya Manusia. Yogyakarta: BPFE

Husen Umar. 2012. Manajemen Personalia dan Sumber Daya Manusia. Edisi 2. Yogyakarta : BPFE

Leon C. Megginson. 2013.Manajemen Sumber Daya Manusia.Yogyakarta : Leberty

Malayu S.P. Hasibuan ～. 2012. Manajemen Sumber Daya Manusia. Jakarta : PT Bumi Aksara.

Mandagie, Susanti, Angel. 2016. Pengaruh Lingkungan kerja, Komunikasi dan stress kerja Terhadap Kinerja Pegawai(Pada Politeknik Kesehatan Manado). Skripsi diterbitkan. Manado. Universitas Sam Ratulangi Manado.

Mathis, R.L. \& J.H. Jackson. 2012.Sumber Daya Manusia. Jakarta : Bumi Aksara. 
Massoudi, Aram, Hanna. 2017. The Consequence Of Work Environment On Employess Productivity. Skripsi diterbitkan. Erbil, Iraq. Cihan University

Moekijat. 2011. Manajemen Sumber Daya Manusia. Bandung : Mandar Maju

Murtaza, Ghulam. 2016. Impact Of Job Stress On Employee Job Satisfaction (DHQ Hospital Of Okara). Skripsi diterbitkan. Pakistan. University RWP.

Prof.Dr. Sugiyono. 2014. Metode Penelitian Pendidikan Pendekatan Kuantitatif, Kualitatif Dan R\&D. Bandung : Alfabeta

Rivai, Veithzal. 2013. Manajemen Sumber Daya Manusia untuk perusahaan (Edisi 3). Jakarta: Rajawali Pers

Rizki Muhammad. 2016. Pengaruh Lingkungan Kerja Terhadap Stres Kerja Karyawan (PT. PLN Distribusi Jawa Timur). Skripsi diterbitkan. Malang. Universitas Brawijaya.

Sahlan, Nurul, Iksan. 2015. Pengaruh Lingkungan Kerja, Kepuasan Kerja, Dan Kompensasi Terhadap Kinerja Karyawan Pada PT Bank SULUT Airmadidi. Skripsi diterbitkan. Malang. Universitas Brawijaya

Samuel,Tulenan. 2015. The Effect Of Work Environment And Compensation Toward Employee Performance (At The Of State Assets And Auction Service). Skripsi Diterbitkan. Pakistan. University RWP.

Sedarmayanti. 2012. Sumber Daya Manusia Dan Produktivitas Kerja. Bandung :Mandar Maju

Sunyoto, D. 2013. Manajemen Sumber Daya Manusia. Yogyakarta : CAPS

Syafii, Mochamad. 2016. Pengaruh Lingkungan Kerja Dan stres Kerja Terhadap Kinerja Karyawan Di Perum Perhutani Kesatuan Bisnis Mandiri Industri Kayu Gresik. Skripsi diterbitkan. Malang : Universitas Brawijaya Malang.

Tjiabrata, Reinhard, Fernando. 2017. Pengaruh Beban Kerja Dan lingkungan Kerja Terhadap Kinerja Karyawan (PT. Sambar Ganda Manado). Skripsi diterbitkan. Manado. Universitas Sam Ratulangi

Wilson Bangun. 2012. Manajemen Sumber Daya Manusia. Jakarta : Erlangga.

Wulandari, Putri, Okta, Inke. 2015. Pengaruh Stres Kerja Dan Lingkungan Kerja Terhadap Prestasi Kerja Pada Karyawan ( PT. Kebon Agung Malang). Skripsi diterbitkan. Malang. Universitas Brawijaya Malang. 